\title{
PARTICIPACIÓN CIUDADANA Y PATRIMONIO CULTURAL: EXPERIENCIAS PARA SU REVALORIZACIÓN, PARROQUIA ANCONCITO, CANTÓN SALINAS
}

\author{
CITIZEN PARTICIPATION AND CULTURAL HERITAGE: \\ EXPERIENCES FOR ITS REVALORATION, ANCONCITO PARISH, \\ CANTÓN SALINAS
}

\author{
Mario Maldonado Rivadeneira ${ }^{1}$ \\ rio max182@hotmail.com \\ Carlos José Castro Granoble ${ }^{1}$ \\ ccastrogranoble@hotmail.com \\ Wilson León Valle ${ }^{1}$ \\ misiowill@yahoo.es \\ ${ }^{1}$ Universidad Estatal Península de Santa Elena, Ecuador \\ Se agradece la colaboración de los tutores: \\ Abg. Agustín Zúñiga $B,(+)$ \\ Lcda. América Meza B, Mg. (+)
}

\section{RESUMEN}

El objetivo principal del ensayo es relacionar la importancia de la participación ciudadana y la valoración objetiva del patrimonio cultural por parte de la comunidad, para lo cual se realizó la revisión literaria de las teorías relacionadas al tema de participación ciudadanía y patrimonio cultural; de la misma manera a nivel general, latinoamericano, nacional y local. También fue llevada a cabo la revisión de artículos científicos afines al tema de investigación, se acudió a la verificación de artículos legales: Constitución de la República del Ecuador 2008, Código Orgánico de Organización Territorial, Autonomía y Descentralización y otras normativas existentes en el Ecuador, en referencia a la participación y patrimonio cultural. El método utilizado para la investigación, fue el descriptivo con enfoque cualitativo y cuantitativo, con abordaje deductivo; mediante la técnica de encuesta y entrevista a los ciudadanos residentes del barrio Twintza, parroquia rural Anconcito, para tener suficiente información con respecto al conocimiento relacionado al tema objeto de estudio; pero se evidenció un contraste entre la valoración teórica del patrimonio y la participación ciudadana. Además no se implementan los mecanismos apropiados que permitan al habitante su participación ciudadana, incrementando la comprensión y apropiación de su entorno patrimonial local, debido a que las instituciones encargadas no cumplen con los roles establecidos en las normativas y por lo tanto no ha sido reconocido en su justo valor por la ciudadanía, para su goce y utilización. En consecuencia no ha provocado mejoras en las condiciones de vida que propone el Buen Vivir.

Palabras clave: participación ciudadana, patrimonio cultural, buen vivir, comunidad, métodos.

\begin{abstract}
The main objective of the trial is to relate the importance of citizen participation and objective assessment of cultural heritage by the community, for which literary theories reviews, Issue citizenship participation and cultural heritage was made; in the same way a general, Latin American, national and local levels. scientific papers related to the research topic was revised, he turned to the verification of legal articles: Constitution of the Republic of Ecuador 2008 Organic Code of Territorial Organization, Autonomy and Decentralization and other existing regulations in Ecuador, referring to participation and cultural heritage. The research method used was descriptive with qualitative and quantitative approach, with deductive approach; through technical survey and interview residents Twintza citizens, rural parish Anconcito neighborhood to have enough information regarding the knowledge related to the subject under study; but a contrast between the theoretical valuation of assets and citizen participation was evident. In addition no appropriate mechanisms that allow the inhabitant their citizen participation are
\end{abstract}


implemented, increasing understanding and ownership of their local heritage environment, because the institutions responsible do not meet the established roles in policy and therefore not recognized in fair value for the public, for the enjoyment and use. Consequently it has not led to improvements in living conditions proposed by the Good Living.

Keywords: citizen participation, cultural heritage, good living, community, methods.

Recibido: 26 de septiembre de 2016

Aceptado: 14 de junio de 2017

Publicado: 31 de julio de 2017

\section{Introducción}

El presente ensayo tiene como objetivo relacionar la importancia de la participación ciudadana y la valoración objetiva del patrimonio cultural por parte de la comunidad, utilizando el arte como un conductor para conseguirlo, se utilizó de referencia teóricas relacionadas a la temática plantada de nuestro objeto de estudio; empezando por (Hermosa, 2000) quien indica que, en Grecia en el siglo V, a.C, nace la democracia y consolida en Atenas, bajo el mandato de Pericles, (Soboul, 1964) manifiesta que la Revolución Francesa a fines del siglo XVIII, contribuyó de manera esencial al cambio social, porque instaura como modelo participativo de Gobierno a la "Asamblea".

(Cunill, 1991) define la Participación Ciudadana como: todas aquellas experiencias que remiten a la intervención de los individuos en actividades públicas para hacer valer intereses sociales, (Bello, 2004) relata que solo las movilizaciones emprendidas por los pueblos originarios, lograron transformar la ausencia del goce de derechos de inclusión política y económica al que estaban históricamente sometidos;.(UNESCO, 1997) establece que son las generaciones actuales las encargadas de cuidar para las nuevas, lo necesario para garantizar el desarrollo socioeconómico en condiciones de Igualdad, sostenibilidad, universalidad, de manera colectiva o individual, administrando de manera sensata y reflexiva los recursos que existan para combatir la pobreza, (Prats,1998) conceptúa al Patrimonio como: Todo aquello que en el ámbito social se considera merecedor de ser preservado, más allá de su valor utilitario, (Yánez, 2012) establece que, el campo del patrimonio Cultural ha sido conocido casi exclusivamente por profesionales especializados en la materia, (Hernández Cardona, 2002) manifiesta que, el grado de civilización de una sociedad se relaciona con la manera en que esta cuide y respete al patrimonio cultural, convirtiéndolo así en fuente de bienestar y riqueza ; de la misma manera se recurrió a las normativas vigente cómo: Constitución de la República del Ecuador
2008, Código Orgánico de Organización Territorial, Autonomía y Descentralización y otras leyes existentes en el Ecuador en referencia a la participación y patrimonio cultural.

Para el trabajo investigativo se aplicó el método descriptivo con enfoqué cualitativo y cuantitativo con abordaje deductivo, mediante la técnica de encuesta y entrevista a los ciudadanos residentes del barrio Twintza, parroquia rural Anconcito, para tener suficiente información con respecto al conocimiento relacionados al tema objeto de nuestro estudio, pero se evidenció un contraste entre la valoración teórica del patrimonio y la participación ciudadana,

En conclusión, no existen mecanismos apropiados que permitan la participación ciudadana, la comprensión y apropiación de su entorno patrimonial local, debido a que las instituciones encargadas no cumplen con los roles establecidos en las normativas, no obstante el lenguaje utilizado no es el adecuado para el tema, por lo tanto, no ha sido reconocido en su justo valor por la ciudadanía para su goce y utilización, en consecuencia, no ha provocado mejoras en las condiciones de vida que propone el Buen Vivir.

\section{Referencias teóricas - conceptuales y normativas} Antecedentes Históricos

Antonio Cruz en su libro "Sociología, una desmitificación" (2002,36p) menciona a Aristóteles, quien sostiene que "el hombre es un animal social", y una de sus características, es su capacidad de asociarse con otros miembros de su especie; ya sea con fines reproductivos o con la finalidad de conseguir de manera asociada algún beneficio común. No se podía concebir una sociedad perfecta para vivir en goce de la felicidad sin estar inmerso en la 
"polis", esto es articulado como familia y dentro de una Ciudad Estado, en donde todos los individuos interactúan entre sí, participando en todas las dimensiones del desarrollo.

En este contexto, podemos entender a la participación, como la facultad de interactuar en un medio determinado y expresar en él, sentimientos, pensamientos, necesidades, tomando decisiones y adquiriendo herramientas para desarrollar la construcción de relaciones, fundamentadas en principios y valores democráticos, que aporten al bien común y por ende al desarrollo humano.

Las primeras formas de participación ciudadana se evidencian en Grecia en el siglo V, a.C, en cuyas Ciudades Estado nace la democracia que se consolida en Atenas, bajo el mandato de Pericles quien contribuyó con sus reformas, convirtiendo a la ciudad en un modelo de desarrollo organizado por sus propios ciudadanos (Hermosa, 2000).

El filósofo griego Aristóteles indica en su libro "Política" que solo se puede considerar ciudadano a quien participa en las decisiones de lo público, esto es el Estado.

En Roma (509 - 27 a.C) se consolida y fortalece la participación ciudadana, con el establecimiento del gobierno mixto, que permite la participación armónica de todos los actores socio políticos.

Al respecto, Polibio manifiesta en su libro "Historia Universal": Las tres formas de Gobierno: Real, Aristocrático y Democrático, deben participar de manera igualitaria, para consolidar la República Romana y de esta manera se evitaría la corrupción; pues cada forma controlaría a las otras, provocando un equilibrio de poder y un balance justo para un Gobierno equitativo (Bobbio, 1987).

En Inglaterra, el "Parlamento" tiene sus antecedentes en el siglo XI, en el que, durante el feudalismo, una especie de asamblea representativa "Curia Regis", daba su opinión al monarca.

La Revolución Francesa a fines del siglo XVIII, contribuyó de manera esencial al cambio social, no solo porque todo el pueblo participa en el derrocamiento de Luis XVI, sino porque instaura como modelo participativo de Gobierno a la "Asamblea" en donde sus integrantes trabajaban investidos de la dignidad de diputados. La decadencia de la forma monárquica de Gobierno provocó una crisis social en todos los estamentos del Estado, provocando el rechazo a la injusta manera de prevalecer de los nobles de clases altas y de la Iglesia que detonó cuando la clase burguesa, artesanos, y especialmente los campesinos, rechazaron las Asambleas realizadas. El 17 de junio de 1789 se conforma la Asamblea Nacional que fue desconocida por el Rey; sin embargo, días después el 24 de junio del mismo año, 47 miembros de la nobleza y el clero se unen a esta Institución, que el 9 de julio es proclamada bajo el nombre de Asamblea Nacional Constituyente (Soboul, 1964).

Pocos días después la revuelta popular agrupada bajo el lema "Libertad, Igualdad, Fraternidad", da como resultado el derrocamiento y muerte de Luis $\mathrm{XVI}$, además, la abolición de muchos privilegios de la nobleza y el clero. Finalmente, el 26 de agosto de 1789 se proclama "La Declaración de los Derechos del hombre y del Ciudadano", que ha servido de inspiración a diferentes Cartas Magnas en todo el planeta.

Con el devenir de los tiempos, la evolución de la práctica política ha permitido y apuntalado el surgimiento de los derechos ciudadanos, entre los cuales, la participación política y su aporte en la toma de decisiones para la construcción del Estado son determinantes en la construcción de un sistema democrático (Pradas, 2007).

Otros autores han enriquecido desde su óptica personal con nuevos conceptos a esta percepción; en ese sentido, Cunill define la Participación Ciudadana como: "todas aquellas experiencias que remiten a la intervención de los individuos en actividades públicas para hacer valer intereses sociales" (Cunill, 1991).

\section{Participación ciudadana en América Latina}

Las primeras formas de organización comunitaria y por ende participativa, las encontramos en las comunidades indígenas, con sus "Consejos Ancestrales o Cabildos Comunales", como herramienta en la toma de decisiones; que han logrado conservar su estructura y propósito original, a pesar de su contacto con civilizaciones ajenas a su naturaleza.

El sistema de organización comunitaria, se ha mantenido prácticamente intacto desde tiempos ancestrales y en algunas regiones de América, se evidencia en la administración de justicia, en donde todo el pueblo participa en la aplicación de las penas impuestas por el Cabildo; lo mismo sucede con la propiedad de la tierra en la que el pueblo administra y posee el territorio, y los miembros de la comuna la hacen prosperar. 
En el año de 1789, el Padre Juan de Velasco publica la "Historia del Reino de Quito", en la que relata cómo se trabajaba la tierra "de forma comunitaria". No obstante que el concepto de ciudadano no se aplicaba en esta forma monárquica de gobierno y se consideraba al Inca como una figura divina, la participación del pueblo era fundamental y solidaria (Velasco, 1789).

El proceso independista colonial de los países latinoamericanos a comienzos del siglo XIX, integra el nuevo concepto de ciudadano al vocabulario político sostiene Darcy Riveiro (1984).

Se debe particularizar el papel de mujeres que dejaron una huella profunda en el cambio social durante la época republicana, y es imposible no reconocerle a Matilde Hidalgo de Procel, ilustre dama lojana, su aporte en lograr que en el año de 1924 se le reconozca su derecho a sufragar en las elecciones de ese año, convirtiéndose en la primera mujer en América Latina en hacerlo (Avilès, s.f).

Este hecho provocó que, en el año de 1929, durante el mandato de Isidro Ayora, nuestro país sea el primero en otorgarles el derecho al voto a las mujeres en Latinoamérica.

Durante la lucha anti-dictatorial en Latinoamérica, la participación surgió de las clases populares desde los años 60, como respuesta a la división de clases sociales, en la que la más alta era la imperante y formaba parte de un sistema político desigual, en el que cualquier proceso de representación popular en el Estado era deslegitimizado.

Los gobiernos latinoamericanos eran dictatoriales y autoritarios, no obstante, en los años 70', en el Perú, Velasco Alvarado planteó propuestas de inclusión, que al no surgir desde la ciudadanía perdieron fuerza.

Al respecto Sonia Fleury, menciona en su artículo "Legitimidad, Estado y Cultura", que surgieron manifestaciones callejeras espontáneas reclamando su inclusión en toma de decisiones, como las del "Movimiento de los Sin Tierra" en Brasil, y en otros países entre estos: Ecuador, Paraguay, Bolivia, México, y Argentina.

Durante los 80', los países latinoamericanos emprendieron en su mayoría el retorno al orden democrático, lo que marcó nuevas expectativas políticas en la región, produciendo tres efectos visibles : la democracia no logró desaparecer sus compromisos con las élites; la predominación del mercado provocó el retroceso del reconocimiento de los derechos sociales; y se estimuló la aparición de algunas organizaciones que aportaron desde las bases populares nuevos contenidos y espacios de participación ciudadana.

A pesar que, en algunos regímenes, los grupos sociales comandaron el fortalecimiento de la democracia, el marco jurídico electoral estaba diseñado para favorecer a los actores políticos comprometidos con los gobiernos, y esto no satisfizo las necesidades socio políticas del pueblo.

Como resultado, surgieron nuevos frentes sociales, con nuevos actores e instituciones más fuertes, el reconocimiento de los derechos se implementó con más vigor; se organizó la sociedad civil, abriendo nuevas instancias de acción y decisión, provocando cambios, no solo en el espacio político; sino también en el administrativo que empezó a integrar a la sociedad.

Una democracia plena necesita de una participación activa de la ciudadanía en todas las expresiones de la vida pública, robusteciendo el tejido social.

El acceso a la información sobre las actividades de las instituciones del Estado, se constituyó en una aspiración ciudadana, sobre su derecho a ser partícipe del engranaje gubernamental, de manera clara y transparente.

Al respecto, (Vleugels, 2011) dice que la gran mayoría de leyes nacionales de acceso a la información pública, se aprobaron en la última década. En este sentido, los gobiernos Latinoamericanos, se han esforzado tratando de establecer nuevos mecanismos participativos en los espacios de decisión pública y preferentemente a nivel municipal.

Esto se ha visto reflejado en: Ecuador, El Salvador, Guatemala, Belice, Brasil, Chile, Colombia, Perú, República Dominicana, Uruguay Honduras, México, y Nicaragua, fortaleciendo el estado de democracia establecido por votación popular (Bandeira, 2013).

La participación ciudadana es fundamental para el desarrollo y la democracia. El Banco Interamericano de Desarrollo (BID), la califica como condición obligatoria para ello, puesto que, mediante sus mecanismos, los ciudadanos pueden influir directamente en la solución de los problemas y así lograr la satisfacción de las necesidades fundamentales para el progreso de las comunidades.

En Latinoamérica, actualmente se están generando nuevas herramientas de interrelación con el Estado por parte de la sociedad civil, provocado por la inexistencia de 
políticas sociales integradoras generadas desde los estamentos gubernamentales, que no cumplen sus propuestas para el desarrollo de la comunidad.

Esta ausencia de apertura hacia la causa social en las políticas públicas por parte del gobierno, ha provocado, que el pueblo genere nuevos espacios propiciadores de dialogo e interacción entre gobierno y sociedad; así como el reconocimiento de derechos de participación y legitimidad a los actores sociales quienes, según Santiago Ortiz en su artículo "La participación ciudadana"; señala a Sonia Fleury (1994), están aportando a una nueva forma de conceptualización de la práctica de la democracia y su integración a los temas de debate.

La demanda social y la auto organización de la sociedad, han actuado cuidando sus intereses, generando un espacio alejado del Estado, motivado por la poca práctica de los derechos en la vida diaria. Estas asociaciones civiles, median organizando la presencia política inmediata ciudadana, aportando insumos para una reforma del Estado, que permita la interacción con los grupos excluidos de la sociedad; siendo esta la contribución más importante de Latinoamérica a la Teoría de la Democracia (Ortiz, s.f).

Pero, además, según la misma autora, estos métodos se contradicen entre sí en América Latina, con respecto a la divulgación de los conceptos vinculantes entre ciudadanía y democracia, debido a la segregación y exclusión de los derechos sociales.

Álvaro Bello sostiene en el libro "Etnicidad y ciudadanía en América Latina", publicado con el auspicio de la Comisión Económica para América Latina y el Caribe (CEPAL) y la ONU, que la conmemoración del quinto siglo del descubrimiento de América, evidenció que solo las movilizaciones emprendidas por los pueblos originarios, lograron transformar la ausencia del goce de derechos de inclusión política y económica al que estaban históricamente sometidos. No se puede de ninguna manera desvalorizar los cuestionamientos surgidos de su rebelión a las formas opresoras de gobierno tradicionales (Bello, 2004).

En el mismo libro, se sostiene que un Estado garantizador de derechos, se construye justamente con los aportes de todos y que los espacios de deliberación y concertación, son el marco para lograr acuerdos y decisiones importantes para la comunidad.
Es en democracia donde el pueblo puede hacer sentir su pensamiento de manera eficaz y la historia así lo demuestra.

\section{Participación Ciudadana en el Ecuador}

No obstante que la Iglesia Católica recién en el año de 1537, aceptó que los indígenas poseían alma y razonamiento como todos los seres humanos, fueron desconocidos sus derechos de igualdad y relegados a tareas campesinas, sufriendo humillaciones, abusos, torturas y muerte.

Eran considerados más al nivel de animales de carga que como seres humanos, lo que fue creando en el indígena, antes dueño de las tierras originarias de la Colonia, un sentimiento de rebelión, que se transformó en muchos levantamientos contra el opresor.

Los pueblos indígenas protagonizaron desde 1535, protestas contra la dominación española, siendo estas las primeras muestras de la participación del individuo, como forma de hacer conocer a los gobernantes, su inconformidad con el sistema vigente (Carlosama, 2000).

Esta chispa rebelde, continuó encendida durante toda la época colonial y determinó, que el 10 de Agosto de 1809, en la ciudad de Quito, con la participación de "marqueses, nobles sin título y ricos criollos", que se decían representantes de los barrios, según narra Alfredo Pareja Diezcanseco en su libro "Ecuador: Historia de la República", se conforme la Junta Suprema de Gobierno, en el primer gesto de rebelión hacia la administración monárquica y que es conocido como el Primer Grito de Independencia; siendo desde entonces nombrada Quito como "Luz de América" (Pareja Diezcanseco, 2009).

Este hecho, fue un antecedente para que el 24 de mayo de 1822, Ecuador alcance su independencia de España.

En 1871 Fernando Daquilema, durante el gobierno de García Moreno, encabeza al movimiento indígena en una sublevación contra la explotación del campesinado, que terminó con su fusilamiento en enero de 1872, pero la protesta ya estaba encendida (Lopez \& Cabrera , 1986).

100 años más tarde de la independencia del Ecuador, el 15 de noviembre de 1922, los sindicatos obreros y el pueblo de Guayaquil se levantan y se toman las calles, reclamando por sus salarios de hambre, en la época depresiva posterior a la Primera Guerra Mundial, siendo 
masacrados y echados a la ría. Su gesta pasó a la historia con el nombre de "Las Cruces sobre el Agua", constituyéndose la primera manifestación multitudinaria del proletariado, contra las oligarquías que controlaban el poder, representado por el General José Luis Tamayo (Gallegos Lara, 1944).

Se debe destacar en el año 1924, el aporte de Matilde Hidalgo de Procel para lograr que, en 1929 se reconozca el derecho a participar en los sufragios nacionales, a las mujeres ecuatorianas.

En 1983 el Frente Unitario de Trabajadores (FUT), convocó a una huelga nacional de 48 horas en las que obreros, transportistas, estudiantes y población rechazaron las medidas económicas impuestas por el gobierno neo-liberal de Oswaldo Hurtado.

El movimiento indígena cada vez más organizado y caracterizado por su lucha infatigable e indeclinable, marcha a Quito en lo que se llamó el Levantamiento del Inti Raimy, en 1990, en 1994 se levantan nuevamente en oposición a la Ley agraria y en el 2001, las medidas impuestas por el FMI que provocaron finalmente el Feriado Bancario, desencadenan nuevas protestas que determinan la salida del Presidente Jamil Mahuad (Fundación Pueblo Indio del Ecuador).

Como se puede ver, las primeras expresiones de participación ciudadana en el Ecuador surgieron como respuesta a las inequidades que el pueblo percibía; la clase obrera unida a los indígenas, protagonizaron jornadas de lucha, manifestada mediante paros y huelgas que la historia recoge, mas no siempre tuvieron la respuesta demandada.

En la provincia de Santa Elena se creó la delegación del Consejo Ciudadano de Participación Ciudadano y Control Social (CPCCS) en el año 2010., un año después de la expedición de la Ley regulatoria por La Asamblea Constituyente el 29 de enero del 2009. Actualmente su delegada cumple con su función acorde a lo establecido por la ley: Promover el ejercicio de los derechos de participación, control social de lo público y rendición de cuentas, a través de los diferentes mecanismos establecido por la constitución. El ciudadano ha ejercido el derecho al voto durante las diferentes instancias de elección popular con el aval y presencia de delegados del CPCCS, fortaleciendo la presencia ciudadana con la conformación de Asambleas Populares Locales en las cabeceras Cantonales y Parroquiales. Además, se han firmado acuerdos para la creación de los Consejos Ciudadanos Barriales en el caso del
Cantón La Libertad (CPCCS, 2016) y convenios con las Universidades locales (CPCCS, 2013).

Los GADs provinciales, cantonales y parroquiales vienen participando en la construcción, aprobación en forma participativa los Planes de Desarrollo y Ordenamiento Territorial (PDOT), así como los presupuestos participativos, los mismos que aprobados en asamblea participativas, se encuentran publicados en fuentes públicas,

\section{Fundamentación legal de la Participación Ciudadana en el Ecuador}

La Constitución Política de La República del Ecuador de 1998, no establece expresamente, el derecho a participar en los asuntos de interés público, pero crea la Comisión de Control Cívico de la Corrupción.

En el 2008, la Constitución de la República del Ecuador instituye los derechos de participación y sus mecanismos de funcionamiento, los cuales constan en los siguientes articulados:

Título II, Capítulo 5to, en los artículos del 61 al 65 , establece los derechos de participación del ciudadano en lo público, así como a organizarse e intervenir en los procesos políticos eleccionarios como electores y elegidos, el derecho al voto y la fiscalización del poder público, Finalmente ordena la participación paritaria de hombres y mujeres en los cargos públicos de nominación, y en partidos, movimientos políticos (...).

El Título IV, Capítulo I, Art 95, instituye que todos las ciudadanas y ciudadanos participarán del control en las de decisiones, gestión y planificación de la cosa pública, cuyas Instituciones serán monitoreadas por la ciudadanía.

La participación está fundamentada por los principios de "autonomía, igualdad, deliberación pública, respeto a la diferencia, interculturalidad solidaridad y control popular".

Finalmente, en el Título IV, Capítulo quinto, se instaura como la Quinta función del Estado, la Transparencia y Control Social, regida por el Consejo de Participación Ciudadana y Control Social (CPCCS), entidad autónoma, que empieza a funcionar transitoriamente desde el 26 de enero del 2009. (Asamblea Constituyente, 2008)

El 18 de marzo de 2010, la Asamblea Nacional posesiona a los consejeros y consejeras del CPCCS (CPCCS, 2015). 


\section{Patrimonio Cultural}

A pesar de que ya en el siglo XVIII, se empezó a mencionar el término patrimonio cultural para identificar a las colecciones artísticas de la época, no es sino hasta el siglo XIX, en que se lo empieza a utilizar para identificar todos los bienes artísticos o monumentales antiguos, que tengan valor extrínseco o intrínseco y a los que se debía proteger y conservar por parte del Estado.

Se debe mencionar al respecto, que en 1931 recién se logra el primer acuerdo internacional sobre protección al patrimonio cultural histórico, arqueológico, artístico y científico en la Carta de Atenas realizada en Guatemala; en la cual, además, ya se empieza a mencionar la protección testimonial de todas las civilizaciones, en clara referencia al patrimonio oral.

Así mismo la convención de la Haya de 1954, favoreció la protección del patrimonio cultural en eventual caso de guerra, incorporando en su artículo 1 puntualmente todo lo que contenga valor histórico o artístico.

Acorde con estos avances, en 1972 en la conferencia dictada por la Organización de las Naciones Unidas para la Educación, la Ciencia y la Cultura (UNESCO), se acuerda la expedición de la Convención de protección del patrimonio sea este cultural o natural, Pero recién en 1984 en la Declaración de México sobre Políticas Culturales se define integralmente lo que constituye el patrimonio cultural (Mejìa, 2014).

La UNESCO en la declaración de la 29. a Conferencia realizada en Paris del 21 de octubre al 12 de noviembre de 1997, artículo 10 , en lo referente a desarrollo y educación, acoge lo manifestado en las anteriores convenciones y afirma que:

Son las generaciones actuales las encargadas de cuidar para las nuevas, lo necesario para garantizar el desarrollo socioeconómico en condiciones de Igualdad, sostenibilidad, universalidad, de manera colectiva o individual, administrando de manera sensata y reflexiva los recursos que existan para combatir la pobreza (UNESCO, 1997).

Al referirnos al patrimonio cultural 0 antropológico, hablamos sobre las manifestaciones de la cultura, es decir las huellas o datos que los humanos dejamos a lo largo de nuestra vida y por los cuales se nos conoce e identifica.
El Patrimonio, identifica a los grupos humanos, la diferencia de otras etnias a través de distintas manifestaciones como la oralidad (leyendas), la arquitectura, los instrumentos de labranza, los textos y crónicas históricas, el arte y los conocimientos sobre las formas de producir. Pero estas manifestaciones grupales 0 individuales, deben ser reconocidas y asumidas por la comunidad. El patrimonio no se define como tal, hasta que no sea incorporado a la forma de vida de la colectividad (Alfonso, 2003).

Lorenz Prats conceptúa el Patrimonio como "Todo aquello que en el ámbito social se considera merecedor de ser preservado, más allá de su valor utilitario" (Prats, 1998).

De igual modo, otra definición aceptada, define al patrimonio cultural como un legado de tipo cultural que atañe a una comunidad en particular, cuyos rasgos de identidad son cuidados y transmitidos a generaciones actuales y futuras.

\section{Participación ciudadana y Patrimonio cultural}

Relacionando Participación, Patrimonio y además inclusión, Civalero manifiesta: "La participación social es fundamental en el momento de la apreciación de lo patrimonial para lograr que la comunidad se sienta incluida, no excluida" (Civalero, 2010).

El campo del patrimonio Cultural ha sido conocido casi exclusivamente por profesionales especializados en la materia, que no han logrado establecer redes que los unan a la ciudadanía; su misma formación tecnocrática ha imposibilitado que la gente común se empodere del tema, disminuyendo el beneficio social que su cabal conocimiento ofrece a la población (Yanez, 2012).

Sin duda alguna no se ha logrado establecer un proceso de comunicación de dos vías, el autoritarismo con que los funcionarios exponen los dogmas establecidos en su formación, intimidan al ciudadano común y lo cohíben. Otra barrera para lograr el interés general y por ende la participación es la desconfianza que existe en la palabra del funcionario, generada por años de promesas incumplidas y entonces lo institucional se vuelve un símbolo al que hay que oponerse (Hanecker, El Troudi, \& Bonilla, 2005).

Así mismo mientras más espacios de participación ciudadana relacionada a conocer las formas de pensamiento, costumbres, quehaceres e historia de la comunidad, se podrá determinar de manera eficaz que es el 
patrimonio cultural para ellos y por consiguiente el éxito de los proyectos que se implementen en este ámbito (Abarzúa, 2005).

Xavier Hernández Cardona manifiesta en su libro "Didáctica de las ciencias sociales, geografía e historia" que el grado de civilización de una sociedad se relaciona con la manera en que esta cuide y respete al patrimonio cultural, convirtiéndolo así en fuente de bienestar y riqueza (Hernandez Cardona, 2002).

Por lo tanto, evidenciamos que existen ventajas, que la participación ciudadana ofrece a los modelos de desarrollo; en el campo de lo cultural, es un instrumento fundamental para permitir que los individuos de una comunidad, se expresen acorde a sus distintas visiones y valores simbólicos, convirtiéndose en los suscitadores de acciones que contribuyan a promover la sostenibilidad; en consecuencia, establecen un compromiso de protección del patrimonio cultural.

En todas las dimensiones del desarrollo no existe validación de las decisiones que a nivel ejecutivo sean implementadas, sin que haya existido la participación constructiva del ciudadano. Es importante considerar qué, las acciones conducentes a su fortalecimiento, inciden de manera positiva en la autovaloración ciudadana, como un sujeto aportante a su comunidad.

\section{Fundamentación histórica y legal de lo patrimonial en la República del Ecuador.}

La conquista del Reino de Quito por los españoles, marcó el inicio de una época de saqueo del gran tesoro ancestral que la cultura indígena precolombina, había producido como parte de su acervo cultural.

Estos bienes se constituyen en las primeras huellas identitarias de nuestra nación, las mismas que en gran parte fueron extraídas de sus sitios de origen y pasaron a formar parte de colecciones privadas fuera de nuestra Patria.

El mestizaje, produjo el desarrollo del arte pictórico y escultórico que dejó para las nuevas generaciones, maravillosas muestras, creadas durante parte del siglo XVI, y los siglos XVII y $\mathrm{XVIII}$; a este conjunto de obras se las conoce como la Escuela Quiteña, gran movimiento creativo que se reflejó principalmente en varias Iglesias; cuyos altares y espacios interiores o exteriores albergaron grandes obras de arte de artistas como Caspicara y Bernardo de Legarda (Aviles, s.f).
Es innegable la poderosa influencia de la Iglesia Católica en esta época y de ahí el enriquecimiento artístico mostrado en sus principales templos. Entre ellos, las Iglesias de la Compañía en Quito, La Catedral de Cuenca entre otras.

Sin embargo, a pesar de la enorme valía de estos tesoros culturales, jamás fueron protegidos de manera efectiva por el Estado; fueron considerados como propiedad de la Iglesia y por lo tanto privados.

En el Ecuador, desde la expedición de la primera Constitución en 1830, han ido incorporándose garantías para la creación cultural; primero para la libertad de opinión y expresión. Luego, en 1835 aparece el derecho a la propiedad intelectual (art. 99).

Pero recién en 1937, se firma un convenio de protección de los bienes patrimoniales pertenecientes al clero, entre el Vaticano y el Estado; y no es sino hasta 1945 (art.144-145) en que se menciona el aporte del Estado a la difusión, apoyo y libertad para la creación artística, reconociendo como tesoro cultural ecuatoriano toda expresión creativa, custodiada y protegida por las leyes de la Republica.

Velasco Ibarra crea la Casa de la Cultura Ecuatoriana en 1944 y en el año 1945 se establece la Ley de Patrimonio Artístico.

Algunos años pasaron, antes de que el Presidente Rodríguez Lara emita la Ley Nacional de Cultura en 1973, a partir de este momento se han generado algunos mecanismos que ponderan el valor de lo patrimonial, y en este sentido el 9 de junio de 1978, se expide la Ley de Patrimonio Cultural, que crea el Instituto de Patrimonio Cultural como la institución del Estado encargada de hacer cumplir esta Ley (Mejìa, 2014).

Sin embargo, la Ley prácticamente fue inobservada en general, por desconocimiento de la misma y por indolencia de las autoridades. Es a partir de la promulgación de la Constitución de la República del Ecuador vigente desde el 2008, que se establecen derechos colectivos de acuerdo a pactos, convenios y declaraciones que contribuyen al fortalecimiento de la protección, defensa y conocimiento de todo lo que comprende al patrimonio cultural; lo que fortaleció los insumos contenidos en dicha Ley, la que fue codificada en el año 2004.

La Constitución de la República del Ecuador 2008; se refiere al ámbito cultural en dos secciones y nueve artículos en total, establecidos en los siguientes articulados: 
El artículo 57, de la carta magna, en su numeral $8^{\circ}$ se expresa sobre la conservación y promoción del manejo de la naturaleza y su biodiversidad.

El Gobierno formulará y pondrá en ejecución programas con la participación comunitaria, para asegurar la preservación y utilización sostenible de la variedad animal y vegetal existente en un ecosistema.

El artículo 405 del mismo texto constitucional, señala que: el Estado proporcionará los recursos económicos necesarios para la estabilidad financiera del sistema, fomentando la participación de las comunidades, pueblos y nacionalidades que han habitado ancestralmente las áreas protegidas, en su administración y gestión; permitiendo que las propias comunidades se apersonen de los recursos naturales y patrimoniales existentes, abogando por establecer mecanismos, para ponerlos en valor y lograr el empoderamiento poblacional de su entorno natural y cultural, especialmente si tienen connotaciones patrimoniales y por ende culturales.

Los Art 377 - 380 y especialmente el Numeral 1 del Art 380, se refieren la patrimonio cultural; estos articulados nos indican que el Sistema Nacional de Cultura (SNC) debe organizar, valorar, fomentar e impulsar; las memorias culturales y formación artísticas; por lo tanto, para su ejecución, estará conformada por organizaciones gubernamentales de cultura, que se regirán por las leyes y reglamentos establecidos; además nos indican el tipo de patrimonio tangible, intangible e identidad cultural que son parte de la nación; sin embargo, para su conservación el Estado tiene la responsabilidad de implementar y crear políticas culturales para garantizar el desarrollo cultural.

El Plan Nacional de Salvaguarda del Patrimonio Cultural Inmaterial (octubre 2011), expresa en su numeral 1.1.3." Ámbitos en los que se manifiesta el Patrimonio Cultural Inmaterial", lo siguiente y citamos:

Todas las manifestaciones y actividades colectivas inmersas en el campo del Patrimonio Cultural Inmaterial, poseen un sentido compartido pleno de conocimientos y creencias únicas, elaboradas en función del entorno particular, articuladas con la naturaleza y la historia y que proveen de un sentimiento de identidad y continuidad (Inmaterial, Plan Nacional de Salvaguarda del Patrimonio Cultural, 2011).

El mismo numeral, habla sobre la relación entre la colectividad y el patrimonio, mencionando de manera clara su aporte a la identidad y la amenaza que los estilos de vida globalizados o influenciados por medios de comunicación masivos, el impacto turístico y el desarrollo económico provocan (UNESCO, 2011).

Existen otros fundamentos legales: el Código Orgánico de Organización Territorial, Autonomía y Descentralización (COOTAD), expedido en el año 2010, establece las competencias y obligaciones que los Gobiernos Autónomos descentralizados tienen para el desarrollo, ejecución de planes, proyectos y acciones dirigidas al desarrollo cultural y patrimonial en concordancia con las políticas que la Constitución determina sobre patrimonio cultural, para este fin se deberá destinar en el presupuesto anual, los recursos necesarios (Art 55, literal h y Art 144) (Nacional A. , 2010).

El Plan Nacional del Buen Vivir 2013-2017 en sus Objetivos 4 y 5 instituye el fortalecimiento de las capacidades de la ciudadanía (...). Además, la construcción de espacios de encuentro común y fortalecimiento de la identidad nacional, pluriculturalidad (...), (SENPLADES, 2013).

\section{Provincia de Santa Elena: Cantón Salinas}

La península de Santa Elena está caracterizada por ser la cuna de culturas prehispánicas que tuvieron todo su esplendor en los tiempos prehispánicos y quienes han dedicado sus mejores esfuerzos a conocer los rasgos antropológicos, que los describen como un pueblo que mantenía una relación muy estrecha con la tierra, a la cual consideraban su madre.

Estos pobladores ancestrales tuvieron el acierto de utilizar jagüeyes y camellones para conducción de agua, lo mismo que las albarradas que servían como reservorio, porque muchas de ellas, lograban mantener agua durante toda la época del año, constituyendo una solución eficiente para recoger las abundantes aguas invernales y poder mantener agua para riego de cultivos y consumo humano (Alvarez, 2005).

A pesar de los procesos de aculturación y la manera cruel en que proscribieron las creencias y los conocimientos ancestrales, hay poblaciones que en su territorio tienen este tipo de soluciones para el cuidado del agua, pero no las usan ni las preservan y sus habitantes ni siquiera perciben la importancia de ellas, lo que equivale a no tomar en cuenta un recurso 
valioso que en la actualidad les puede servir para garantizar proyectos sustentables.

La importancia del descubrimiento de la cultura Las Vegas, de más de ocho mil años en la península de Santa Elena, desencadenó gran cantidad de visitas de arqueólogos y antropólogos sociales, buscando expresiones culturales de mayor antigüedad, convirtiendo a Santa Elena en su momento, en el territorio más estudiado del Ecuador, beneficiando a algunas de las expresiones prehispánicas y entre ellas el conocimiento de la Cultura Valdivia, a pesar de ser la segunda cultura hallada es quien aporto con la cerámica primigenia del continente. Un tema fundamental es lo relativo a las maneras en que los cultivadores ancestrales idearon soluciones para convertir estos terrenos en utilizables para la agricultura, continuando con la tradición de milenios, de aprovechar las sinuosidades del terreno para hacer encierros donde quedaba atrapada el agua, para posteriormente utilizarla en tiempos de sequía.

Las albarradas fueron un recurso propio del ingenio de los agricultores en esta tierra donde la crudeza de las temporadas de lluvia, desplaza grandes volúmenes de agua, fluyendo hasta el mar y, arrastrando al fondo marino toda clase de nutrientes (Valdez, 2006).

Se debe resaltar el hecho que las principales poblaciones de la Provincia de Santa Elena: la capital del mismo nombre, La Libertad y Salinas, se constituyeron cerca de una albarrada; el cantón Salinas tiene como una de sus características la presencia de albarradas en sus parroquias Muey (José Luis Tamayo) y Anconcito. Desde la primera, antiguamente se repartía a lomo de mula y en barriles de guayacán, agua para todas las poblaciones circundantes. Además, la pesca tradicional artesanal con atarraya, actualmente casi desparecida y las salineras son otra parte representativa de la historia e identidad salínense.

En la parroquia Anconcito del cantón Salinas, provincia de Santa Elena, encontramos que los valores patrimoniales de la zona conocida como Twintza situada a un costado de la albarrada, residen no solo en la presencia de patrimonio natural que constituyen todo su entorno: acantilados, albarradas, playas, sino también personas vinculadas a la pesca artesanal, tradiciones culinarias y portadoras de un acervo cultural que es parte del imaginario que constituyen sus rasgos étnicos y que los diferencia notablemente de los pobladores del interior de la provincia asociados a la agricultura de ciclo corto.
Los rasgos culturales que identifican a cada comunidad ante un mundo globalizado, estimulan la revalorización cultural de las comunidades, al mismo tiempo que se afirma su identidad.

Durante el periodo 2013 - 2015, estudiantes de la Carrera de Organización y Desarrollo Comunitario (ORDECO), estuvieron cercanos a la población de Anconcito, cantón Salinas. Su interés fundamental era empoderar a la ciudadanía local en el conocimiento de su entorno, que su vida diaria se nutriera de los valores que la historia, la naturaleza, la tradición, ha forjado dentro de la comunidad, confiriéndole una particularidad identitaria que los hace únicos.

El centro de actividades fue el barrio popular conocido como Twintza, situado a un costado de la albarrada ancestral de Anconcito y donde habitan aproximadamente 900 personas, distribuidas en 250 viviendas según nos informaron las autoridades del GAD Parroquial Rural de Anconcito (2014).

Ya en el 2013, en unión de técnicos del Instituto Nacional de Patrimonio Cultural INPC, se realizó una capacitación, a la que fueron invitados los estudiantes de ORDECO de la Universidad Península de Santa Elena (UPSE). El lenguaje técnico utilizado por los capacitadores, no logró trasmitir el mensaje que se pretendía inculcar y más bien provocó una especie de incomodidad por parte de la población presente, constituida en su mayor parte por sencillas amas de casa y su núcleo familiar, quienes hacían esfuerzos por descifrar palabras jamás escuchadas y que son normales en el argot técnico profesional de un entendido de patrimonio y cultura.

A partir de esto, para lograr el empoderamiento de la ciudadanía sobre el conocimiento y revalorización del Patrimonio Cultural del barrio Twintza y Anconcito, ORDECO implementó talleres utilizando herramientas artísticas, como la fotografía, la música, y la gastronomía, que al ser compartidas con la comunidad, logró de manera entretenida y participativa, inculcar a los asistentes, el interés por conservar, proteger y utilizar su entorno; fortaleciendo la autoestima y así provocando un incremento en el deseo de involucrarse en más iniciativas de desarrollo (ORDECO 5.1, 2015).

Se debe señalar que, en el Plan de Ordenamiento y desarrollo Territorial, se indica la necesidad de aprendizaje de la ciudadanía en la práctica participativa, que los involucre en la toma de decisiones que posibiliten el bienestar comunitario (Santa Elena E.P, 2015). 
Existen antecedentes respecto a la utilización de herramientas artísticas para fortalecer la participación ciudadana y el conocimiento de lo patrimonial, en este sentido, la UNESCO desarrolló en la comunidad de Chiapas, México, talleres de participación comunitaria, denominados "Identificación de valores patrimoniales culturales y naturales para la gestión local del desarrollo sustentable", utilizando una técnica metodológica participativa de identificación de valores y amenazas al patrimonio que utilizó al dibujo como técnica de expresión colectiva, se armaron diferentes mesas con niños, niñas, hombres y mujeres jóvenes, logrando que la comunidad reconozca estos bienes y valores presentes en su cotidianidad y que al incorporarse a su conocimiento fueron revalorizados (UNESCO, 2010).

Hay que resaltar que la Prefectura del Guayas implementó en Playas, provincia del Guayas, el Proyecto "Balsas con Memoria", en la que artistas y pescadores comandados por el maestro Hernán Zúñiga Albán, pintaron en el velamen de las balsas tradicionales asociadas a las culturas Valdivia (del 4.000 al 2.000 a.C.) y Guancavilca (del 500 a.C. al 1.500 d.C.), la historia ancestral y de Playas (Vistazo, cultura, 2015).

Este proyecto se está actualmente implementando bajo la coordinación del maestro Joaquín Serrano, con la participación de estudiantes, pintores, gestores culturales, provocando de manera directa la revalorización popular del patrimonio cultural (Revista mensual de Turismo y Eventos, 2011).

\section{Materiales y métodos}

El método para la investigación, fue el descriptivo con enfoque cualitativo y cuantitativo con abordaje deductivo. Para obtener la información se utilizó la técnica de la encuesta, que consistió en la elaboración de un cuestionario diseñado para medir el grado de conocimiento de la población con relación a participación ciudadana y patrimonio cultural, además, se entrevistó a personalidades con vasta experiencia en estos temas. Una vez concluidas las encuestas se recopiló la información y se procedió al procesamiento de datos, mediante la base de datos en Excel; estableciendo las características de la población y sus percepciones sobre el objeto de estudio.

Por otro lado, entre los materiales utilizados en la investigación, está la revisión bibliográfica, con consultas a libros, artículos, documentos de sitios web validos como: Dialnet, Scielo, Redalyc, google académico, google books, informes, revistas con datos relacionados al artículo trabajado.

La localidad objeto de estudio, estuvo compuesta por un total de 900 habitantes, de la cual se procedió a extraer una muestra estratificada simple, que resultó en 269 personas, con un nivel de confianza del 95\% y un margen de error +- 5\%, cuya edad fluctúa entre los 16 a 70 años, que son residentes permanentes del Barrio Twintza de la parroquia rural Anconcito, cantón Salinas, provincia de Santa Elena; se estableció esta jerarquía porque en la norma constitucional vigente, se establece que a partir de los dieciséis años los ciudadanos tienen derecho a voz y voto facultativo así como las personas mayores adultas.

\section{Análisis de la información empírica y resultados}

El propósito principal de esta investigación, es el tener suficiente información de los moradores del barrio Twintza, de la parroquia rural Anconcito, cantón Salinas, provincia de Santa Elena, con respecto a la participación ciudadana y patrimonio cultural.

En este contexto la información recolectada sirve para que la comunidad a través de los procesos de participación ciudadana, proteja y expanda su acervo cultural.

Cabe señalar que los habitantes de este sector, indicaron estar dispuestos a conocer sobre sus valores patrimoniales, a través de talleres, utilizando herramientas artísticas como la gastronomía, música y la fotografía para realzar su acervo cultural, ya que las instituciones encargadas de promover y difundir lo cultural, no han considerado sus opiniones y no participan en proyectos 0 iniciativas concernientes a lo cultural.

Según el grafico 1 nos indica que, el $25 \%$ manifestaron que son miembros de una organización de carácter social, mientras que el $75 \%$ indicaron que no pertenecen a ninguna Institución.

Estos datos nos indican, que la ciudadanía del Barrio Twintza de la parroquia Anconcito, cantón Salinas; desconoce que la participación ciudadana genera espacios representativos, para la toma de decisiones en las actividades públicas, así como mecanismos, que aportan al desarrollo local, fortaleciendo la democracia representativa, mediante la integración de la comunidad. 
Gráfico 1 ¿Pertenece a alguna Organización?

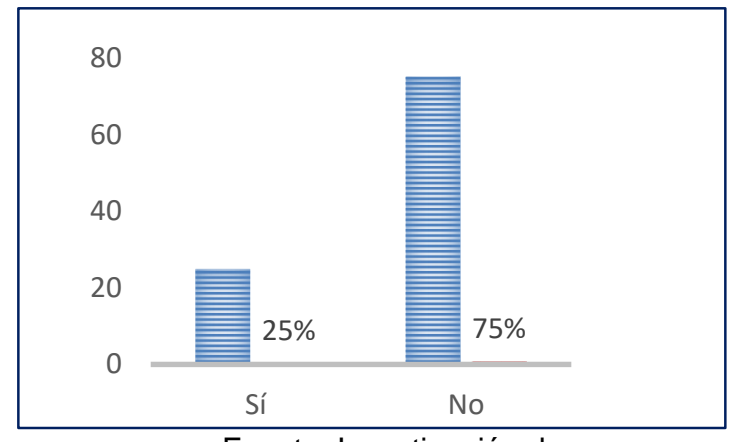

Fuente: Investigación de campo

Elaborado por: Mario Maldonado y Carlos Castro

El $98 \%$ señalaron que tiene instrucción primaria, y el $1 \%$ expresaron tener instrucción secundaria y el $1 \%$ que no poseen ningún nivel de estudio.

El $100 \%$ opinaron que desconocen lo concerniente a los valores culturales que posee la comunidad en donde residen.

El $29 \%$ manifestaron tener un limitado conocimiento referente a los valores patrimoniales y el $71 \%$ revelaron no tener nociones del tema en referencia.

\section{Gráfico 7 Conocimiento de los Valores} Patrimoniales

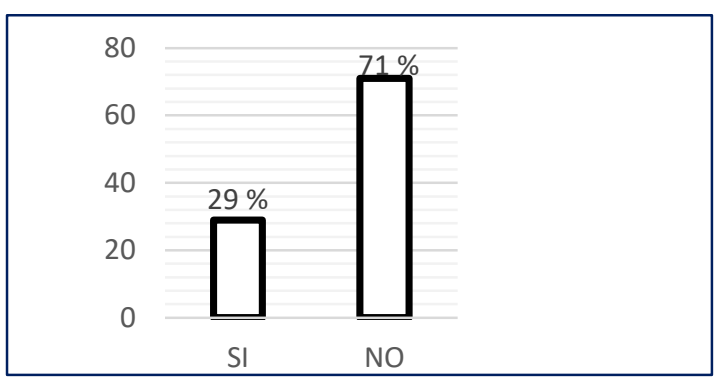

Fuente: Investigación de campo

Elaborado por: Mario Maldonado y Carlos Castro

Estos datos nos indican, que la población admite un desconocimiento de los valores patrimoniales, que son la herencia cultural de una comunidad para las nuevas generaciones y de esta manera, fortalecer el respeto a los saberes ancestrales, la cultura y las prácticas tradicionales locales, que contribuyen al desarrollo sostenible local y el derecho a mantener, controlar, proteger y desarrollar su patrimonio cultural.

El $34 \%$ establecieron que los valores patrimoniales son las tradiciones, el $18 \%$ las costumbres, el $17 \%$ las formas del lenguaje y el $31 \%$ las artesanías.

El 100\% manifestó, no haber participado en ningún proyecto o iniciativa de preservación de los valores patrimoniales.
El 99\% expusieron estar dispuestos a participar en actividades organizadas para instruirse más sobre valores patrimoniales y el $1 \%$ que no participarían.

El $24 \%$ expresaron que estarían dispuestos a participar en charlas, el $20 \%$ en cursos, el $7 \%$ otro tipo de actividades y el $49 \%$ manifestó que participarían en talleres 0 actividades relacionadas a lo cultural.

\section{Entrevistas}

La socióloga Marcela Miranda, P. (13 abril 2016). Comunicación personal. Consejera principal del CPCCS durante los años 2010 2015, sostuvo la importancia que tiene el patrimonio cultural, dentro de la preservación de la herencia que las comunidades venideras reciben de las actuales, en este sentido su experiencia dentro de una Asamblea Ciudadana en Anconcito, le permitió conocer el interés de la población en su historia; y reconoció la validez de las herramientas artísticas como un medio para ampliar la participación ciudadana.

Considerando que el patrimonio cultural de una comunidad/ pueblo es la herencia que poseen la ciudadanía, para su presente y futuro. Esta debe ser expresada desde esa ciudadanía que al permanecer activa puede conservarla y defenderla. La participación ciudadana es la expresión que parte desde lo más básico en una cuadra, en un barrio en una comunidad, manifestada desde la gestión, vigilancia, propuestas".

Esto fue ampliado y corroborado por la Lic. Erika Espín, R. (11 abril 2016). Comunicación personal. Señala:

Lo patrimonial será una razón de cohesión social positiva para la activación de la participación y gestión ciudadana. En tiempos de gran individualismo es importante que se rescaten los espacios públicos, las dinámicas sociales de relacionamiento comunitario y el patrimonio como una razón para la integración comunitaria y el desarrollo de acciones en beneficio de la misma.

Además, señaló que el arte es una de las herramientas de mayor valoración para desarrollar el conocimiento de lo patrimonial.

Edwin Rojas. (7 mayo 2016). Comunicación personal. Presidente del GAD Parroquial de Anconcito, fue enfático en puntualizar que la participación ciudadana se había visto fortalecida en su comunidad y que la utilización de las herramientas artísticas utilizadas por 
ORDECO, habían logrado un cambio positivo, pues la relación directa del ciudadano con su entorno patrimonial; tuvo como consecuencia una ciudadanía mucho más activa

Finalmente, la Sra. Narcisa Mendoza. (7 mayo 2016). Comunicación personal. Habitante del barrio Twintza y una de las coordinadoras en la zona, confirmó el cambio provocado con esta iniciativa de la UPSE dentro de su espacio de Vinculación con la comunidad; al mismo tiempo señaló que la población esperaba continuar siendo capacitada durante más tiempo.

\section{Discusión y presentación de hallazgos relevantes}

Es evidente el contraste entre la valoración teórica del patrimonio y la participación ciudadana, puesto que un porcentaje mayoritario de las personas encuestadas no habían tenido ninguna experiencia con respecto al objeto de estudio, la fundamentación teórica y valoración de estas dos dimensiones del desarrollo no ha estado al alcance de todos, de acuerdo a los datos estadísticas.

En el barrio Twintza de la parroquia Anconcito, cantón Salinas; a través del estudio de investigación mediante la técnica de encuesta, los datos nos indica que, desconocen que la participación ciudadana genera espacios representativos, para la toma de decisiones en las actividades públicas, así como mecanismos, que aportan al desarrollo local, fortaleciendo la democracia representativa, mediante la integración de la comunidad como lo manifiesta (Pradas, 2007), (Cunill, 1991), por consiguiente, admiten un desconocimiento de los valores patrimoniales, que son la herencia cultural de una comunidad para las nuevas generaciones y de esta manera, fortalecer el respeto a los saberes ancestrales, la cultura y las prácticas tradicionales locales, que contribuyen al desarrollo sostenible local y el derecho a mantener, controlar, proteger y desarrollar su patrimonio cultural, tal como define (UNESCO, 1997), (Alfonso, 2003), (Prats, 1998).

La participación social es fundamental en el momento de la apreciación de lo patrimonial para lograr que la comunidad se sienta incluida, no excluida (Civalero, 2010) y que el grado de civilización de una sociedad se relaciona con la manera en que esta cuide y respete al patrimonio cultural, convirtiéndolo así en fuente de bienestar y riqueza (Hernández Cardona, 2002), en el barrio Twintza la ciudadanía expresaron participar en talleres utilizando herramientas artísticas para fortalecer la participacion ciudadana y el conocimiento de lo patrimonial, como las utilizadas por (UNESCO, 2010) y (Vistazo, cultura, 2015) a pesar que, la mayoría de la población tienen instrucción primaria para contradecir lo que expresa (Hernández Cardona, 2002).

\section{Conclusiones}

Es indudable la relación entre participación ciudadana y patrimonio cultural, si la ciudadanía no participa en los talleres e iniciativas que se provoquen en y con la comunidad, no habrá aportes válidos que fortalezcan estas dos dimensiones. Este detrimento de los valores patrimoniales ha provocado un fenómeno aculturizante, en el cual otros modelos de vida han tomado ventaja, volvemos a la circunstancia antes descrita del impacto negativo de la globalización por el mal manejo y uso de la información cultural.

Así pues, no existen mecanismos apropiados que permitan la participación ciudadana, y la comprensión y apropiación de su entorno patrimonial local, debido a que las instituciones encargadas no cumplen con los roles establecidos en las normativas para este fin específicos. El lenguaje técnico utilizado, no ha provocado la respuesta buscada en la interrelación entre el o los técnicos y la ciudadanía que encuentra aburridas, incomprensibles y sin mucha utilidad estos talleres.

En definitiva, el Patrimonio no ha sido reconocido en su justo valor por la ciudadanía y por tanto su goce y utilización, no ha provocado mejoras en las condiciones de vida que propone el Buen Vivir. El limitado conocimiento sobre el patrimonio en toda su extensión, ha impedido los beneficios que la presencia material e inmaterial del mismo, aporta a dimensiones tan importantes como la cultura, la identidad y la autoestima. Los temas patrimoniales, han sido difundidos de manera referencial, no se ha tomado en cuenta a la ciudadanía para hacerla partícipe de talleres informativos 0 de capacitación sobre el patrimonio, provocando confusión y desconocimiento de su significancia y valor. La ley de patrimonio que es el marco legal para la protección de estos bienes colectivos es desconocida e irrespetada, por las autoridades, provocando profundas contradicciones entre la propuesta del buen vivir y la destrucción del entorno natural patrimonial.

Finalmente, no se ha establecido un modelo educativo que capacite a los niños, jóvenes y 
adultos, en estos ítems, considerando que esta es una de las causas fundamentales de esta falencia en el campo cultural. Esto ha provocado apatía e indiferencia ciudadana, inducidos mediáticamente, en temas sin importancia y aporte a su diario vivir; la población está poco acostumbrada a leer, producto de la información globalizada existente, que privilegia el culto a la banalidad, que es una de las características de la sociedad de consumo.

\section{Referencias}

1. (s.f.). Obtenido de http://ipce.mcu.es/pdfs/PNPatrimoniolnmat erial.pdf

2. Asamblea Constituyente. (2008).

Constituciòn 2008. Obtenido de http://www.produccion.gob.ec/wpcontent/uploads/downloads/2012/07/Norma s_Constitucionales.pdf

3. Congreso Nacional. Unesco. (R. Oficial, Ed.) Recuperado el 29 de Abril de 2016, de http://www.unesco.org/culture/natlaws/medi a/pdf/ecuador/ec_codificacion_27_ley_de_ patrimonio_cultural_spaorof.pdf

4. CPCCS. (06 de 11 de 2013). Obtenido de http://www.cpccs.gob.ec/docs/niceditUploa ds/tempo/146133877323-CONVUNIVERSIDAD\%20ESTATAL\%20PENI\%C C\%81NSULA\%20DE\%20STA\%20ELENA. pdf

5. CPCCS. (11 de 06 de 2015). Obtenido de http://www.cpccs.gob.ec/?mod=somos

6. CPCCS. (1 de 08 de 2016). Obtenido de http://www.cpccs.gob.ec/?mod=foro_post\&i $d=3567$

7. Ecuador a colores. (Mayo de 2011). Recuperado el 13 de Abril de 2016, de http://www.ecuadoracolores.com/ed2011_ may/pages/page_01.html

8. Fundación Pueblo Indio del Ecuador. (s.f.). Recuperado el 3 de Mayo de 2016, de http://puebloindio.tripod.com/levantamiento s.html

9. Inmaterial, Plan Nacional de Salvaguarda del Patrimonio Cultural. (2011). Patrimonio Cultrural e Inmaterial.
10. Nacional, A. Código Orgánico de Organización Territorial,Autonomía y Descentralización. Quito: Ministerio de Coordinación de la Política. 2010.

11.ORDECO 5.1. Informe de Vinculación con la comunidad. 2015. Académico, UPSE, La Llbertad.

12. Revista Vistazo. Recuperado el 13 de Abril de 2016, de http://vistazo.com/seccion/cultura/balsastradici\%C3\%B3n-que-se-mantiene-desdelas-culturas-valdivia-y-huancavilca

13.Santa Elena E.P. Plan de Desarrollo y Ordenamiento Teritorial de la parroquia Anconcito 2015. Tecnico, UPSE, Santa Elena E.P, La Libertad. Obtenido de http://app.sni.gob.ec/visorseguimiento/Desc argaGAD/data/sigadplusdiagnostico/09685 51090001_PDyOT_DG_ANCONCITO_1505-2015_05-56-01.pdf

14.UNESCO. Paris: UNESCO. Recuperado el 17 de 12 de 2014, de http://portal.unesco.org/es/ev.phpURL_ID $=13178 \& U R L$ DO=DO_TOPIC\&UR L_SECTION=201.html

15.UNESCO. "Identificación de valores patrimoniales culturales y naturales para la gestión del desarrollo sustentable.

Recuperado el 20 de enero de 2015, de UNESCO:

http://www.unesco.org/new/fileadmin/MULT IMEDIA/HQ/CLT/pdf/el_Mexico_OCOSING O\%20workshop.pdf

16.UNESCO. Plan Nacional de Salvaguarda del Patrimonio cultural inmaterial.

Recuperado el 19 de Diciembre de 2014, de

http://ipce.mcu.es/pdfs/PNPatrimoniolnmat erial.pdf

17.Vleugels, R. LLRX.COM. Obtenido de http://www.Ilrx.com/features/foilawsovervie w.htm

18.www.definicionabc.com > General. (06 de 03 de 2016). Obtenido de http://www.definicionabc.com/general/patri monio-cultural.php 